\title{
Variable shape of magnetic hysteresis loops in the Chinese loess-paleosol sequence
}

\author{
Koji Fukuma* and Masayuki Torii \\ Division of Earth and Planetary Sciences, Graduate School of Science, Kyoto University, Kyoto 606-01, Japan
}

(Received May 15, 1997; Revised October 13, 1997; Accepted October 14, 1997)

\begin{abstract}
Shape of magnetic hysteresis loops of the Chinese loess-paleosol sequence is variable with low-field susceptibility and is weakly constricted in samples with intermediate susceptibility $\left(\sim 1.0 \times 10^{-6} \mathrm{~m}^{3} / \mathrm{kg}\right)$. The analyses of the hysteresis loops show that both low- (ferrimagnetic) and high-coercivity (antiferromagnetic) components are present and the ferrimagnetic component dominate the magnetic characteristics. The ratio of ferrimagnetic over antiferromagnetic minerals ( $\mathrm{S}$ ratio) and the superparamagnetic fraction increase with increasing susceptibility. Neither simple two-component mixtures of ferrimagnetic and antiferromagnetic minerals nor of single-domain and superparamagnetic grains fully explain the constricted hysteresis loops. We interpret the variation of the loop shape with susceptibility in the following way. When the ratio of the ferrimagnetic to antiferromagnetic contribution is relatively low (low susceptibility), the broad loop is controlled by lithogenic ferrimagnetic and antiferromagnetic minerals. For samples with intermediate susceptibility values, constricted shape originates from an addition of a broad loop from the lithogenic fraction and a narrow loop from a pedogenic fraction with high superparamagnetic content. Then with further susceptibility increase, the constricted shape almost disappears and the loop is dominated by the pedogenic fraction. The variation of hysteresis loop shape with susceptibility can be a useful indicator of the degree of pedogenesis for loess-paleosol samples.
\end{abstract}

\section{Introduction}

The striking similarity between the magnetic susceptibility variation of the Chinese loess-paleosol sequence and the variation of the oxygen isotope of deep sea sediments (Heller and Liu, 1984, 1986; Kukla et al., 1988) has stimulated an enormous number of rock magnetic studies on the mechanism linking the susceptibility variation and paleoclimate (Heller and Evans, 1995). Various types of magnetic properties, including susceptibility, remanence and hysteresis properties, have been measured on samples collected from various sites of the Chinese Loess Plateau. Hysteresis data on the Chinese loess-paleosol sequence have been reported by several authors (Liu et al., 1992; Rolph et al., 1993; Eyre and Shaw, 1994; Heller and Evans, 1995; Hunt et al., 1995; Sun et al., 1995). However, in many cases only limited kinds of hysteresis parameters (e.g., saturation magnetization) were used for interpretation and the hysteresis data have not been fully analyzed.

Arguably hysteresis measurements are the most fundamental means of characterizing magnetic materials, but the interpretation of hysteresis data is not straightforward. Many factors, including magnetic mineralogy, grain size, and so on, can affect hysteresis properties. Since a sensitive and less time-consuming magnetometer for measuring hysteresis properties became available (Flanders, 1988), it has been increasingly recognized that distorted hysteresis loops, such

*Present address: Deep Sea Research Department, Japan Marine Science and Technology Center, Natsushima-cho 2-15, Yokosuka, Kanagawa 237, Japan.

Copy right $($ C) The Society of Geomagnetism and Earth, Planetary and Space Sciences (SGEPSS); The Seismological Society of Japan; The Volcanological Society of Japan; The Geodetic Society of Japan; The Japanese Society for Planetary Sciences. as potbellied (spreading at the middle of loops) or waspwaisted (constricted at the middle of loops), commonly occur in rocks and sediments (e.g., Jackson, 1990; Borradaile etal., 1993; Pick and Tauxe, 1994; Roberts et al., 1995). These distorted hysteresis loops originate from mixed assemblage of multiple magnetic components with different mineralogy or grain size. Now it is necessary to examine hysteresis loops carefully and infer underlying magnetic components for the interpretation of hysteresis properties.

We show hysteresis loops from the Chinese loess-paleosol samples collected from the Luochuan area of the eastern part of the Chinese Loess Plateau (Sasajima and Wang, 1984). Shape of the hysteresis loops varies with low-field susceptibility $\left(\chi_{l f}\right)$. We examine the variation of magnetic parameters reflecting the magnetic mineralogy or grain size with $\chi_{l f}$, and show that both varying mineralogy and grain size with magnetic enhancement cause the variable shape of hysteresis loops.

\section{Samples and Methods}

We collected oriented block samples from the almost vertical cliff wall at two localities, Qinjiazhai and Potou, along Heimugou River. Total thickness of the loess-paleosol sequence at these localities is $138 \mathrm{~m}$, from the present surface to the uncomformable boundary with the Pliocene Red Clay (Sasajima and Wang, 1984). The whole section, consisting of the Malan, Lishi, and Wucheng loess members, was dated back to about 2 Ma by magnetostratigraphy (Torii et al., 1984). For room-temperature hysteresis and low-field susceptibility measurements, we used 98 samples from the upper $90 \mathrm{~m}$ of the section (Malan and Lishi members), from the top of L1 ( $2 \mathrm{~m}$ below the surface) to L15 (90 m below the surface), covering the last $1.5 \mathrm{~m} . \mathrm{y}$. 
Hysteresis measurements were performed with an alternating gradient force magnetometer (MicroMag) at the Institute for Rock Magnetism of the University of Minnesota. For each sample a complete hysteresis loop was obtained with a maximum field of $1.0 \mathrm{~T}$. Saturation magnetization $\left(M_{\mathrm{s}}\right)$, saturation remanence $\left(M_{\mathrm{rs}}\right)$ and coercivity $\left(B_{\mathrm{c}}\right)$ were calculated after subtracting the paramagnetic contribution. Paramagnetic susceptibility $\left(\chi_{p}\right)$ was calculated by fitting the portion between 0.7 and $1.0 \mathrm{~T}$. Remanent coercivity $\left(B_{\mathrm{cr}}\right)$ were measured by applying a maximum field of $1.0 \mathrm{~T}$ followed by a succession of increasing back field values. Isothermal remanent magnetization (IRM) was also measured with the same facility by applying fields in a stepwise manners up to $1.0 \mathrm{~T}$. The $\mathrm{S}$ ratio is defined as the ratio of IRM at the steps of 0.3 and $1.0 \mathrm{~T}$ (Bloemendal et al., 1988). Lowfield susceptibility $\left(\chi_{l f}\right)$ was measured with a Bartington susceptibility meter in the low-frequency mode $(0.47 \mathrm{kHz})$ at Kyoto University.

To identify magnetic minerals, thermal demagnetization of composite IRMs (Lowrie, 1990) was performed after samples were packed in small quartz tubes (length: $10 \mathrm{~mm}$, diameter: $3 \mathrm{~mm}$ ). A magnetic field of $5 \mathrm{~T}$ was applied along the tube's axis and then a field of $0.3 \mathrm{~T}$ was applied perpendicular to the axis. The resulting remanent magnetization was measured with a Schonstedt spinner magnetometer, by using a special plastic holder which can fix the orientation of the tubes to improve the accuracy of orientation of magnetizations.

\section{Results}

On average, loess samples (average $\chi_{l f}=6.67 \pm 3.84 \times$ $10^{-7} \mathrm{~m}^{3} / \mathrm{kg}$, average $M_{\mathrm{s}}=4.94 \pm 1.92 \times 10^{-2} \mathrm{Am}^{2} / \mathrm{kg}$, number $=47)$ are more weakly magnetized than paleosol samples (average $\chi_{l f}=1.39 \pm 0.60 \times 10^{-6} \mathrm{~m}^{3} / \mathrm{kg}$, average $M_{\mathrm{s}}$ $=8.08 \pm 2.83 \times 10^{-2} \mathrm{Am}^{2} / \mathrm{kg}$, number $\left.=51\right)$. The average $B_{\mathrm{c}}$ are $12.7 \pm 3.1 \mathrm{mT}$ for loess samples and $9.8 \pm 2.3 \mathrm{mT}$ for paleosol samples, and $B_{\mathrm{c}}$ steadily decreases with increasing $\chi_{l f}$.

The width and the degree of constriction of hysteresis loops systematically varies with increasing $\chi_{l f}$. Samples with lowest $\chi_{l f}$ in our sample suite show slightly constricted loops with the largest width (Fig. 1(a)); the loops do not close even at $0.5 \mathrm{~T}$ being suggestive of a significant content of antiferromagnetic minerals. Constriction appears pronounced for samples with intermediate values of $\chi_{l f}$ (Fig. 1(b)). These hysteresis loops are narrower especially at the middle of the loops and result in constricted shapes. Paleosol samples with high $\chi_{l f}$ show narrow hysteresis loops and the constriction is largely suppressed (Fig. 1(c)). We could not find any obvious potbellied hysteresis loop in our samples. $M_{\mathrm{rs}} / M_{\mathrm{s}}$ was plotted against $B_{\mathrm{cr}} / B_{\mathrm{c}}$ on a so-called Day plot (Day et al., 1977) (Fig. 2). Most points fall in the pseudo-single domain region, and are well clustered but slightly spread along the $B_{\mathrm{cr}} / B_{\mathrm{c}}$ axis. Loess and paleosol samples did not show significant difference in $M_{\mathrm{rs}} / M_{\mathrm{s}}$, but loess samples exhibited rather higher $B_{\mathrm{cr}} / B_{\mathrm{c}}$ than paleosol samples. The higher $B_{\mathrm{cr}} /$ $B_{\mathrm{c}}$ values for loess samples were associated with the constricted hysteresis loops, as previously reported for natural and synthetic samples (e.g., Roberts et al., 1995)

The difference of magnetization $(\Delta M)$ between ascending

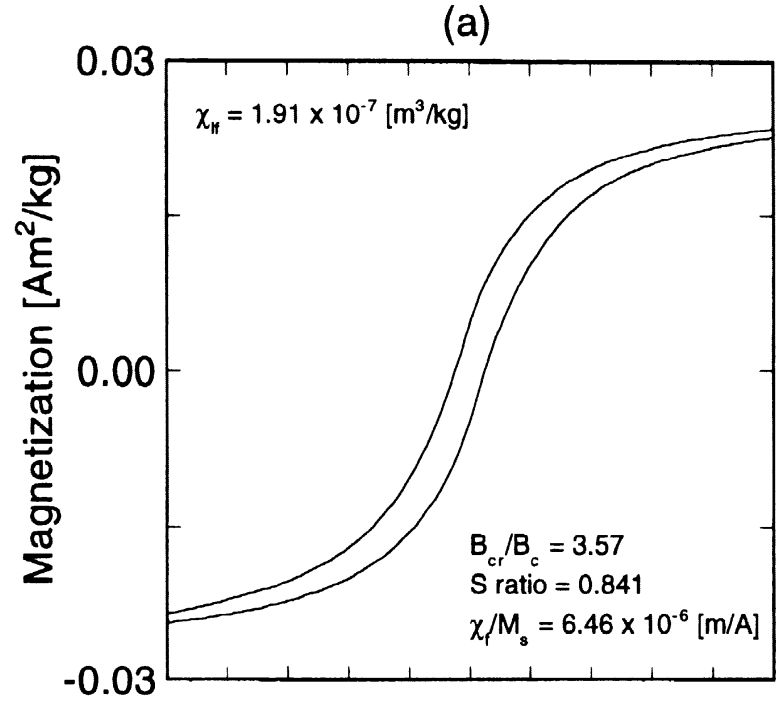

(b)

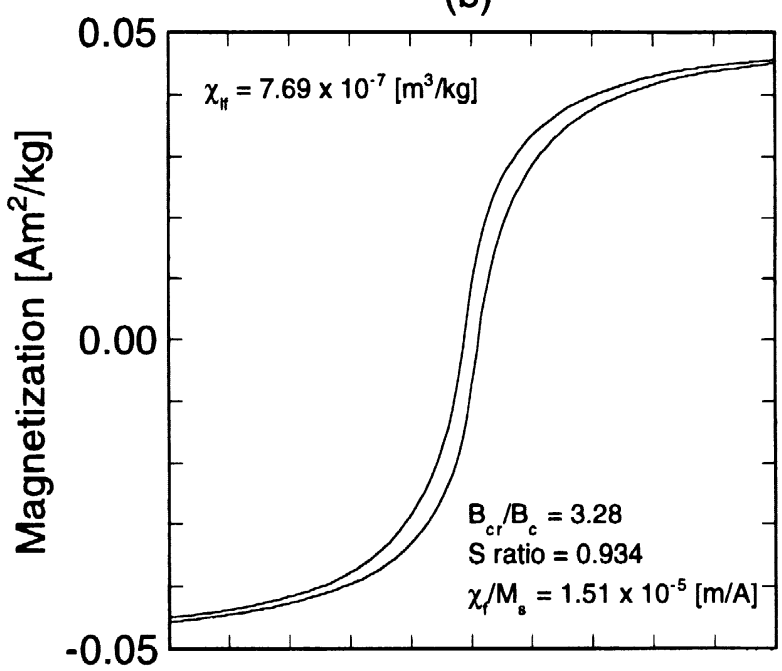

(c)

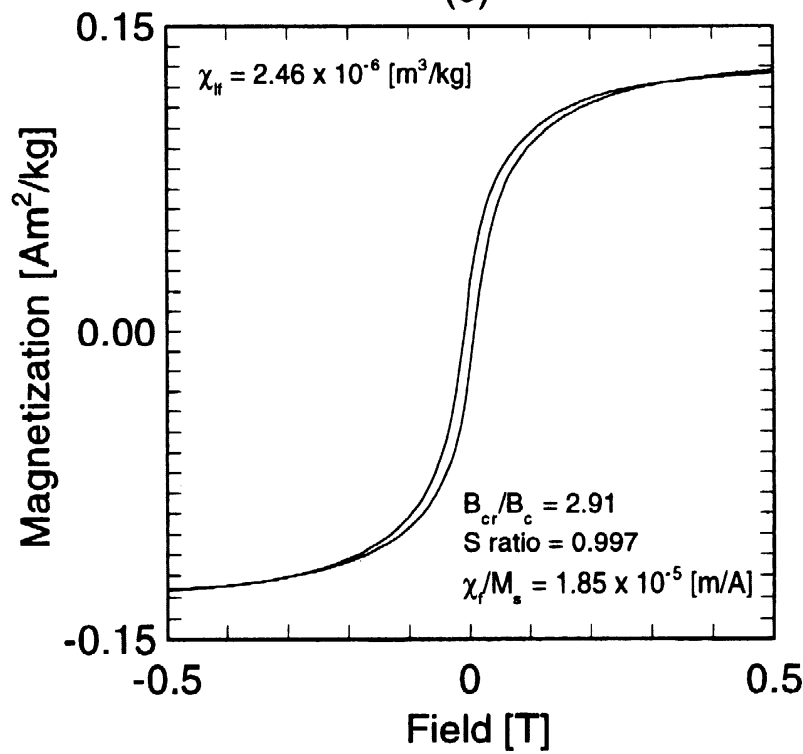

Fig. 1. Examples of hysteresis loops for (a) low low-field susceptibility $\left(\chi_{l f}\right)$ samples, (b) intermediate $\chi_{l f}$ samples, and (c) high $\chi_{l f}$ samples. The hysteresis loops were obtained with a maximum field of $1.0 \mathrm{~T}$ but displayed between -0.5 and $0.5 \mathrm{~T}$. Paramagnetic contributions were subtracted (i.e., the loops are shown after slope-correction). $B_{\mathrm{cr}} / B_{\mathrm{c}}$, $\chi_{f} / M_{\mathrm{S}}$ and $\mathrm{S}$ ratio are explained in text. 


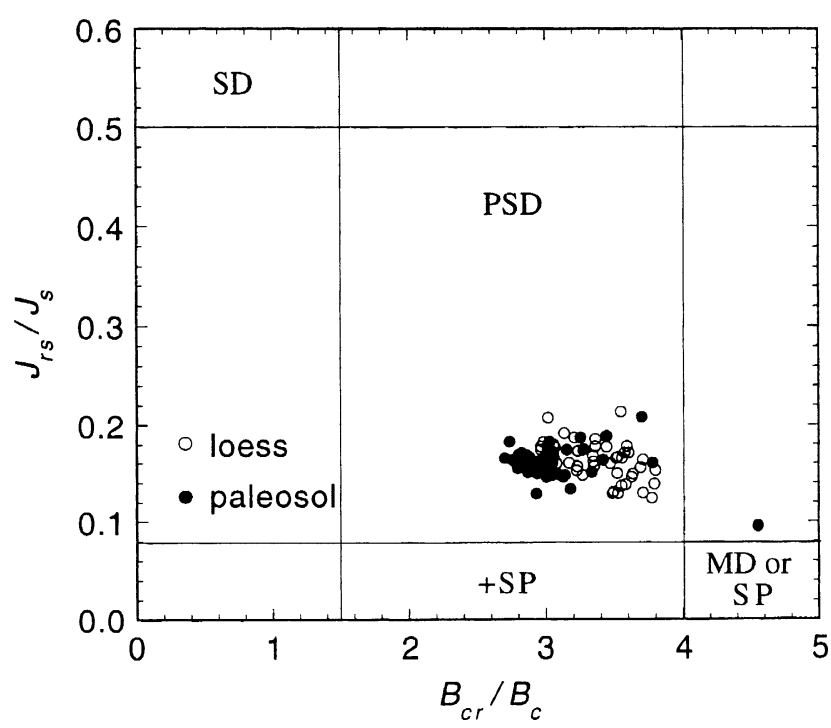

Fig. 2. The ratio of saturation remanence and saturation magnetization $\left(M_{\mathrm{rs}} / M_{\mathrm{s}}\right)$ and remanent coercivity and coercivity $\left(B_{\mathrm{cr}} / B_{\mathrm{c}}\right)$ are plotted for loess (open circles) and paleosol (solid circles) samples. $B_{\mathrm{cr}} / B_{\mathrm{c}}$ are higher for loess samples compared to paleosol samples.

(a)

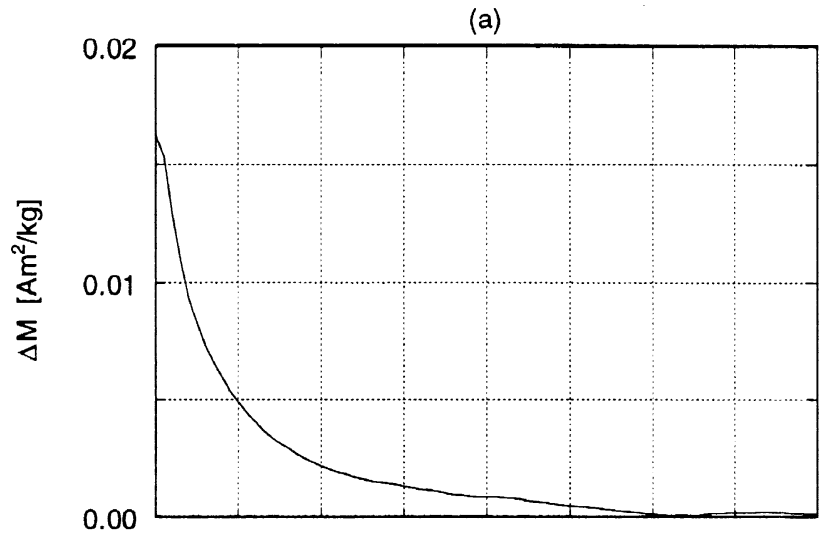

(b)

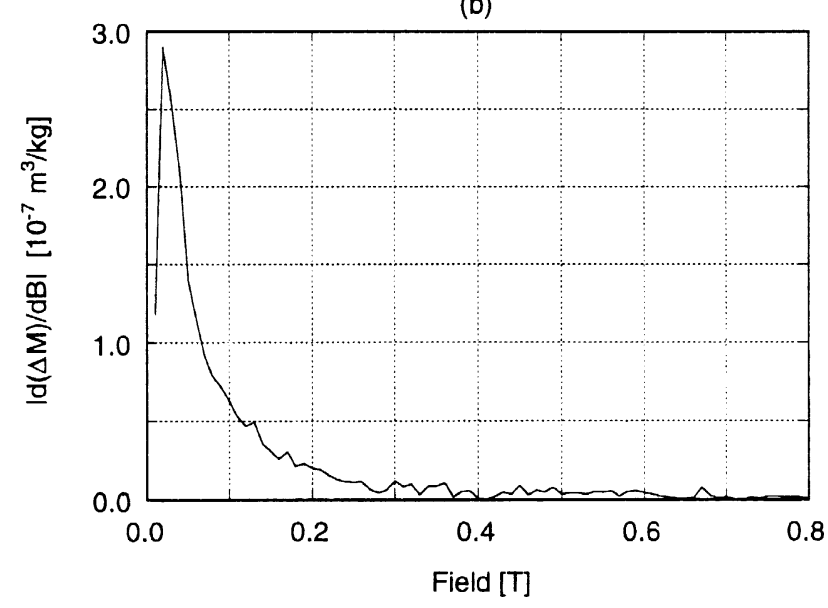

Fig. 3. (a) The $\Delta M$ curves, and (b) the derivative of $\Delta M(d \Delta M / d B)$ curve (Tauxe et al., 1996) for a sample shown in Fig. 1(b). and descending portions of hysteresis loops can be used to distinguish the magnetic component causing distorted hysteresis loops (Tauxe et al., 1996). One example of a $\Delta M$ curve for a sample with a pronounced constricted loop (Fig. 1(b)) is shown in Fig. 3(a). The $\Delta M$ curve rapidly decreases in a seemingly monotonic fashion, but does not reach zero until about $0.6 \mathrm{~T}$. The derivative of the $\Delta M$ curves $(d \Delta M / d B)$ can reveal the distribution of coercivities more clearly. A single peak at about $15 \mathrm{mT}$ is noticeable for the sample (Fig. 3(b)). The monotonic decrease of the $\Delta M$ curve and the

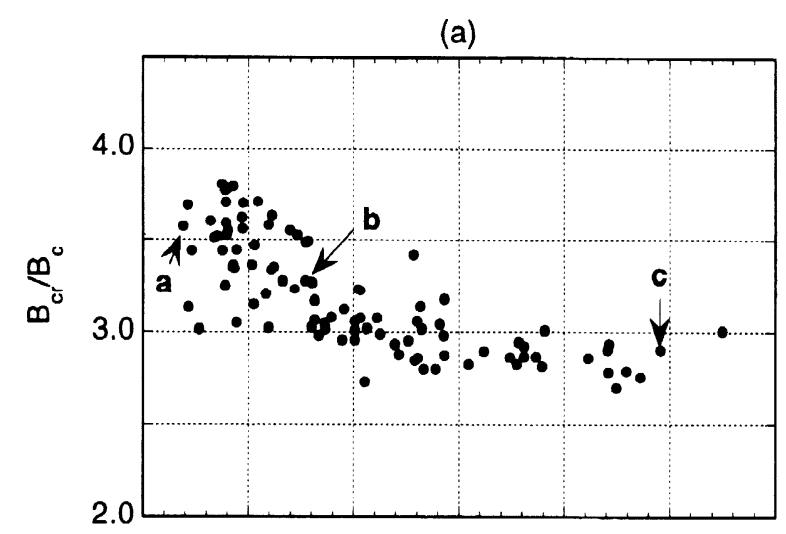

(b)

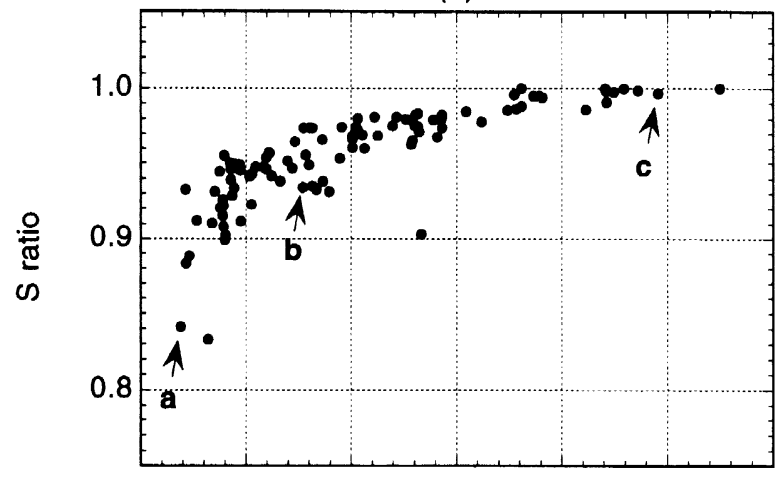

(c)

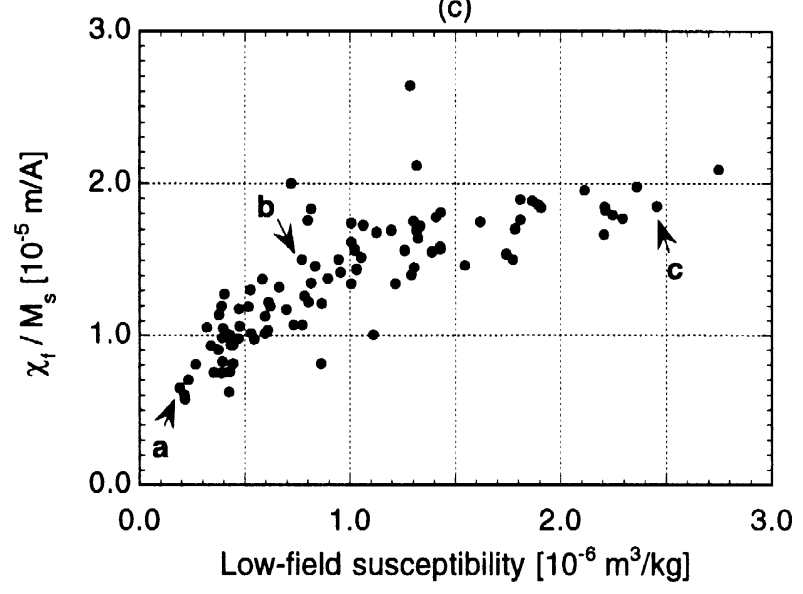

Fig. 4. Variations of (a) the ratio of remanent coercivity to coercivity $\left(B_{\mathrm{cr}}\right.$ l $B_{\mathrm{c}}$ ), (b) $\mathrm{S}$ ratio, and (c) the ratio of ferromagnetic susceptibility to saturation magnetization $\left(\chi_{f} / M_{\mathrm{s}}\right)$ with low-field susceptibility $\left(\chi_{l f}\right)$. Characters "a", "b", and "c" denote the points of samples shown in Figs. 1(a), 1(b), and 1(c), respectively. 
single peak in the $d \Delta M / d B$ curve suggest that a low coercivity (ferrimagnetic) component is dominant. A high coercivity (antiferromagnetic) component is also present, as suggested by the non-zero $\Delta M$ in high field $(>0.3 \mathrm{~T})$, but the concentration is not high enough to give rise to another peak in the $d \Delta M / d B$ curve.

The variation of $B_{\mathrm{cr}} / B_{\mathrm{c}}$, ferrimagnetic/antiferromagnetic ratios (S ratio) and SP fractions with $\chi_{l f}$ are examined (Fig. 4). $B_{\mathrm{cr}} / B_{\mathrm{c}}$, which was reported to be positively correlated with the degree of constriction (e.g., Muttoni, 1995), roughly decreases with increasing $\chi_{l f}$, but the correlation between $B_{\mathrm{cr}} / B_{\mathrm{c}}$ and $\chi_{l f}$ is not very strong (Fig. 4(a)). For the Chinese loess-paleosol samples, the constriction is not strong and the values of $B_{\mathrm{cr}} / B_{\mathrm{c}}$ are relatively low (less than 4). In this case, $B_{\mathrm{cr}} / B_{\mathrm{c}}$ may be not a sensitive parameter for measuring the degree of constriction. The $\mathrm{S}$ ratio (Bloemendal et al., 1988), which is the measure of a ratio of remanence-carrying ferrimagnetic to antiferromagnetic minerals, also increases and approaches unity with increasing $\chi_{l f}$ (Fig. 4(b)). These data suggest that increased ferrimagnetic minerals become more important over antiferromagnetic minerals in high $\chi_{l f}$ samples, although ferrimagnetic minerals are abundant even in the lowest $\chi_{l f}$ samples (S ratios $>0.8$ ). SP fractions are reasonably well measured with the ratio of ferromagnetic susceptibility $\left(\chi_{f}=\chi_{l f}-\chi_{p}\right)$ and $M_{\mathrm{s}}$ (Hunt et al., 1995). $\chi_{f} / M_{\mathrm{s}}$ is plotted against $\chi_{l f}$ in Fig. 4(c). The minimum value of $\chi_{f}$ ' $M_{\mathrm{s}}$ in our sample suite is very close to the value obtained by
Hunt et al. (1995). Increasing $\chi_{f} / M_{\mathrm{s}}$ with $\chi_{l f}$ indicates that SP fraction is higher in high $\chi_{l f}$ samples.

Composite IRMs, which were imparted mutually perpendicularly at $5 \mathrm{~T}$ and then at $0.3 \mathrm{~T}$, were subjected to progressive thermal demagnetization for three selected samples: a loess (L2)/paleosol (S1) couplet and a least weathered sandy loess (L15). We found major kinks around $300^{\circ} \mathrm{C}$ and $580^{\circ} \mathrm{C}$ on soft components $(<0.3 \mathrm{~T})$ for all the three samples (Figs. 5(a), 5(b), and 5(c)), suggesting the presence of maghemite and magnetite, respectively. Comparing the paleosol (Fig. 5(a)) and its parental loess (Fig. 5(b)), the magnetization decreases associated with the kinks are larger for the paleosol sample. Slight kinks near $100^{\circ} \mathrm{C}$, suggesting the presence of goethite, were seen on the hard component (0.3-5 T) of the paleosol (Fig. 5(a)) and on the soft components of two loess samples (Figs. 5(b) and 5(c)). For the hard components, clear kinks above $670^{\circ} \mathrm{C}$ can be found for all the three samples (Fig. 5(d)). This is unambiguous evidence of hematite for both loess and paleosol, because in the case of thermal demagnetization of composite IRMs hematite cannot be mistaken as an oxidation or inversion product during laboratory heating unlike thermal demagnetization of single component IRM (Heller and Liu, 1984; Heller et al., 1991) or thermomagnetic analyses.

\section{Discussion and Conclusions}

The Curie temperatures of Ti-free magnetite $\left(578^{\circ} \mathrm{C}\right)$
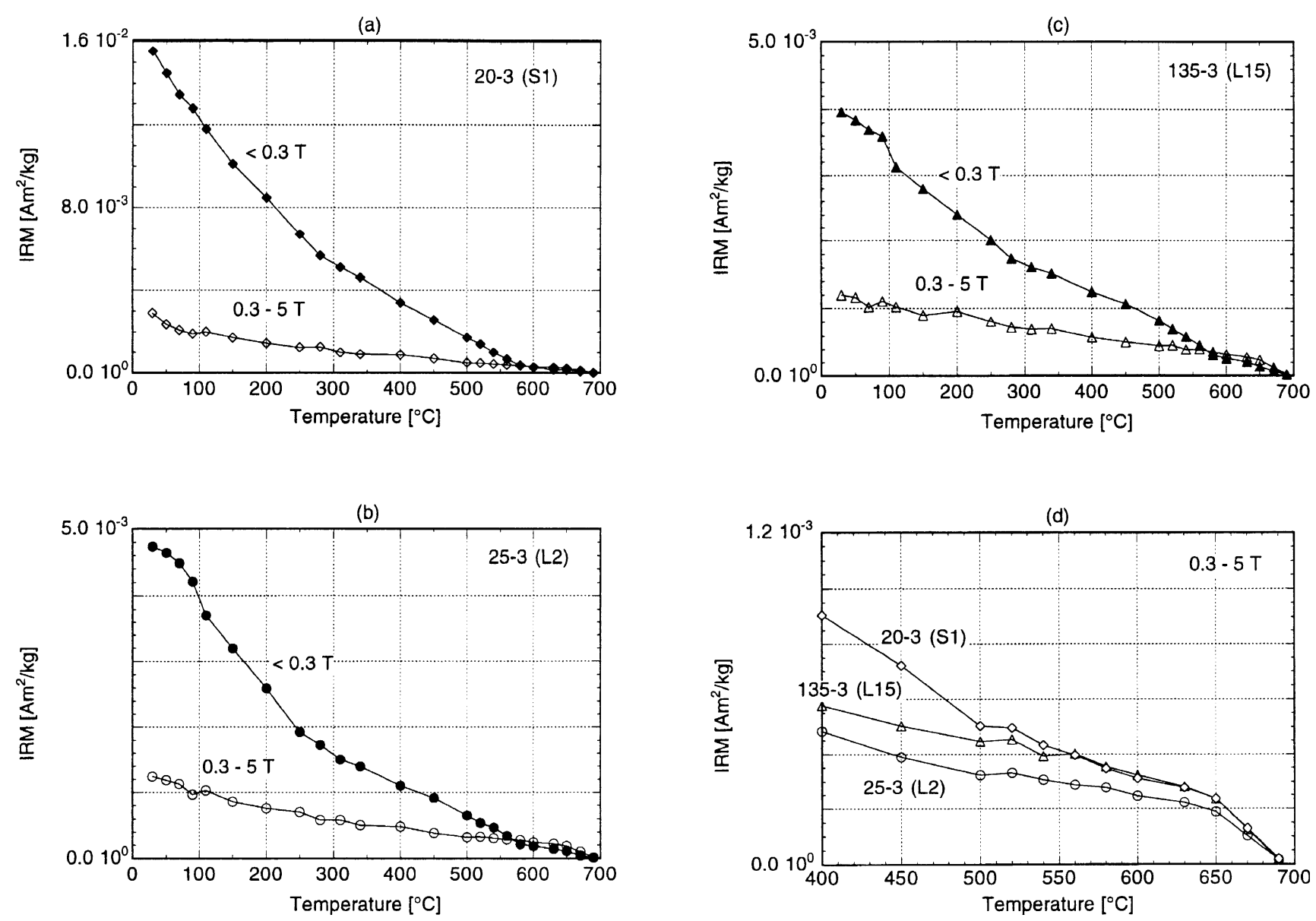

Fig. 5. Thermal demagnetization of composite IRMs induced $<0.3 \mathrm{~T}$ (soft) and 0.3-5 T (hard) for a (a) paleosol/(b) loess couplet, and (c) sandy loess. (d) Enlarged for hard components between 400 and $700^{\circ} \mathrm{C}$. 
have been reported on samples from various sites in the Chinese Loess Plateau (Heller et al., 1991; Maher and Thompson, 1992; Rolph et al., 1993; Evans and Heller, 1994). Thermal demagnetization of composite IRMs indicated that magnetite primarily contributes to the IRM acquired at 0.3 $\mathrm{T}$ for both loess and paleosol and is enhanced in the paleosol (Fig. 5). Maghemite was detected by inflections near $300^{\circ} \mathrm{C}$ on demagnetization curves of the soft IRM components $(<0.3 \mathrm{~T})$ (Fig. 5), as previously found with thermomagnetic analyses (Heller et al., 1991; Maher and Thompson, 1992; Rolph et al., 1993; Evans and Heller, 1994). These data confirm the presence of maghemite in bulk samples for both loess and paleosol, which was previously identified by Mössbauer spectroscopy analyses on magnetic extracts (Vandenberghe et al., 1992; Hunt et al., 1995) or inferred from the CBD technique combined with magnetic measurements (Verosub et al., 1993; Fine et al., 1995; Sun et al., 1995). We also found that hematite is originally present in both loess and paleosol, and the concentration is similar in the loess and paleosol (Fig. 5(d)) contrary to those of magnetite and maghemite. This finding supports the previous reports for hematite in the Chinese loess-paleosol sequence by using reflected microscope and X-ray diffraction (Heller and Liu, 1984) and Mössbauer spectroscopy analyses on bulk samples (Vandenberghe et al., 1992; Eyre and Dickson, 1995; Hunt et al., 1995). The presence of goethite, which was suggested by Mössbauer spectroscopy analyses (Vandenberghe et al., 1992; Eyre and Dickson, 1995), is inferred from very light inflections near $100^{\circ} \mathrm{C}$ of thermal demagnetization of composite IRMs (Fig. 5), but the comprehensive magnetic characteristics of goethite in the Chinese loess-paleosol sequence is still unknown. We suggest that the ferrimagnetic component in the Chinese loesspaleosol consist of magnetite and maghemite and the antiferromagnetic component mainly comes from hematite and possibly goethite.

The grain size of the enhanced ferrimagnetic minerals is believed to lie near SP/SD boundary based on various magnetic properties (Zhou et al., 1990; Heller et al., 1991; Maher and Thompson, 1991). Unambiguous evidence for SP grains was provided by thermal demagnetization of lowtemperature saturation remanence (Banerjee et al., 1993; Eyre and Shaw, 1994; Hunt et al., 1995; Sun et al., 1995). The fraction of SP grains increases in paleosols and is regarded as a reliable measure of pedogenesis (Hunt et al., 1995). The remanence properties of the enhanced ferrimagnetic minerals are quite uniform through various sites of the Chinese Loess Plateau, suggesting to some authors a bacterial magnetite origin (Evans and Heller, 1994).

Both mixtures of ferrimagnetic and antiferromagnetic minerals (Wasilewski, 1973), and of SD and SP grains (Tauxe et al., 1996), can give rise to constricted hysteresis loops. All of these magnetic components are present in the Chinese loess-paleosol samples, and the ratio of ferrimagnetic and antiferromagnetic minerals (S ratio) and the SP fraction $\left(\chi / M_{\mathrm{S}}\right)$, both increase with increasing low-field susceptibility $\left(\chi_{l f}\right)$ (Fig. 4). According to the criteria of Tauxe et al. (1996), the monotonic decrease of the $\Delta M$ curves and the single peak of the $d \Delta M / d B$ curve (Fig. 3) may suggest that the constricted loops are caused by a mixture of
SP and SD grains. However, the constricted shape is rather suppressed in high $\chi_{l f}$ samples with a higher fraction of SP grains (Figs. 1 and 4). On the other hand, a high content of antiferromagnetic minerals mixed with ferrimagnetic minerals can cause constricted shapes (Roberts et al., 1995). The lowest $\chi_{l f}$ samples, which possess the highest antiferromagnetic fractions (lowest $\mathrm{S}$ ratio) (Fig. 4), exhibit slightly constricted loops (Fig. 1(a)). However, the hysteresis loops do not simply become less constricted with the relative decrease of the antiferromagnetic contribution (increasing $\chi_{l f}$ ), but show more pronounced constricted shapes for intermediate $\chi_{l f}$ samples (Fig. 1(b)). Such constricted shapes cannot be attributed to simple two-component mixtures either of ferrimagnetic and antiferromagnetic minerals or of SD and SP grains. All of these magnetic components contribute to the constricted shapes of the Chinese loess-paleosol samples to some extent depending on varying $\chi_{l f}$.

We interpret the variation of the loop shape with low-field susceptibility $\left(\chi_{l f}\right)$ as follows. When the ratio of the ferrimagnetic to antiferromagnetic contribution is relatively low (low $\chi_{l f}$ ), the broad and slightly constricted loop (Fig. 1(a)) is controlled by the lithogenic ferrimagnetic and antiferromagnetic minerals. The enhanced pedogenic magnetic component, comprising ferrimagnetic SD and SP grains (Zhou et al., 1990; Heller et al., 1991; Maher and Thompson, 1991), would probably possess a narrow hysteresis loop. By adding the narrow hysteresis loop of the enhanced component to the broad hysteresis loop of the original lithogenic component (similar to Fig. 1(a)), the constricted shape become more pronounced in intermediate $\chi_{l f}$ samples (Becker, 1982) (Fig. 1(b)). Then with further increasing $\chi_{l f}$, the constricted shape almost disappears as the loop becomes dominated by the increased SP fraction. Narrow and almost normal shaped hysteresis loops of high $\chi_{l f}$ samples (Fig. 1(c)) are due to the high SP fraction. The variation of hysteresis loop shapes with $\chi_{l f}$ can be a useful indicator of the degree of pedogenesis for loess-paleosol samples.

Acknowledgments. We thank Tim Rolph and an anonymous reviewer for valuable suggestions. The loess-paleosol samples were collected during the inter-university collaboration program between Kyoto University (Japan) and Xibei University (China) from 1981 to 1983 (S. Sasajima and Y.-Y. Wang). This research was supported by a Fellowship of the Japan Society for the Promotion of Science for Japanese Junior Scientists and a grantin-aid for scientific research of Ministry of Education of Japan (No. 04640702) to K.F. The Institute for Rock Magnetism at the University of Minnesota, which is funded by the Keck Foundation, the US National Science Foundation, and the University of Minnesota, allowed K.F. to use its facilities.

\section{References}

Banerjee, S., C. P. Hunt, and X.-M. Liu, Separation of local signals from the regional paleomonsoon record of the Chinese Loess Plateau: A rock magnetic approach, Geophys. Res. Lett., 20, 843-846, 1993.

Becker, J. J., Surface effects on hysteresis loop shapes in high-coerciveforce crystallized amorphous alloys, IEEE Trans. Magn., MAG-18, 1451-1453, 1982.

Bloemendal, J., B. Lamb, and J. W. King, Paleoenvironmental implications of rock-magnetic properties of late Quaternary sediment cores from the eastern equatorial Atlantic, Paleocenography, 3, 61-87, 1988.

Borradaile, G. J., N. Chow, and T. Werner, Magnetic hysteresis of 
limestones: Facies control?, Phys. Earth Planet. Inter., 76, 241-252, 1993.

Day, R., M. Fuller, and V. A. Schmidt, Hysteresis properties of titanomagnetites: grain-size and compositional dependence, Phys. Earth Planet. Inter., 13, 260-267, 1977.

Evans, M. E. and F. Heller, Magnetic enhancement and palaeoclimate: Study of a loess/paleosol couplet across the Loess Plateau of China, Geophys. J. Int., 117, 257-264, 1994.

Eyre, J. K. and D. P. E. Dickson, Mössbauer spectroscopy analysis of iron-containing minerals in the Chinese loess, J. Geophys. Res., 100 17925-17930, 1995.

Eyre, J. K. and J. Shaw, Magnetic enhancement of Chinese loess-the role of $\left\langle\mathrm{Fe}_{2} \mathrm{O}_{3}\right.$ ?, Geophys. J. Int., 117, 265-271, 1994.

Fine, P., K. L. Verosub, and M. J. Singer, Pedogenic and lithogenic contributions to the magnetic susceptibility record of the Chinese loess/paleosol sequence, Geophys. J. Int., 122, 97-107, 1995.

Flanders, P. J., An alternating gradient force magnetometer, J. Appl. Phys., 63, 3940-3945, 1988.

Heller, F. and M. E. Evans, Loess magnetism, Rev. Geophys., 33, 211 240, 1995.

Heller, F. and T. Liu, Magnetism of Chinese loess deposits, Geophys. J. R. astr. Soc., 77, 125-141, 1984.

Heller, F. and T. Liu, Paleoclimatic and sedimentary history from magnetic susceptibility of loess in China, Geophys. Res. Lett., 13, 1169_ 1172,1986

Heller, F., X. Liu, T. Liu, and T. Xu, Magnetic susceptibility of loess in China, Earth Planet. Sci. Lett., 103, 301-310, 1991.

Hunt, C. P., S. K. Banerjee, J. Han, P. A. Solheid, E. Oches, W. Sun, and T.-S. Liu, Rock-magnetic proxies of climate changes in the loesspalaeosol sequences of the western Loess Plateau of China, Geophys. J. Int., 123, 232-244, 1995.

Jackson, M., Diagenetic sources of stable remanence in remagnetized carbonates: A rock magnetic study, J. Geophys. Res., 95, 2753-2761, 1990.

Kukla, G., F. Heller, L. X. Ming, X. T. Chun, T. S. Liu, and Z. S. An, Pleistocene climates in China dated by magnetic susceptibility, Geology, 16, 811-814, 1988 .

Liu, X., J. Show, T. Liu, F. Heller, and B. Yuan, Magnetic mineralogy of Chinese loess and its significance, Geophys. J. Int., 108, 301-308, 1992.

Lowrie, W., Identification of ferromagnetic minerals in a rock by coercivity and unblocking temperature properties, Geophys. Res. Lett., 17, 159-162, 1990.

Maher, B. A. and R. Thompson, Mineral magnetic record of the Chinese loess and paleosols, Geology, 19, 3-6, 1991.
Maher, B. A. and R. Thompson, Paleoclimatic significance of the mineral magnetic record of the Chinese loess and paleosols, Quat. Res., 37, 155170, 1992.

Muttoni, G., "Wasp-waisted" hysteresis loops from a pyrrhotite and magnetite-bearing remagnetized Triassic limestone, Geophys. Res. Lett., 22, 3167-3170, 1995.

Pick, T. and L. Tauxe, Characteristics of magnetite in submarine basaltic glass, Geophys. J. Int., 119, 116-128, 1994.

Roberts, A. P., Y. Cui, and K. L. Verosub, Wasp-waisted hysteresis loops: Mineral magnetic characteristics and discrimination of components in mixed magnetic system, J. Geophys. Res., 100, 17909-17924, 1995.

Rolph, T. C., J. Shaw, E. Derbyshire, and J. T. Wang, The magnetic mineralogy of a loess section near Lanzhou, China, in The Dynamics and Environmental Context of Aeolian Sedimentary Systems, edited by K. Pye, pp. 311-323, Geological Society, London, 1993.

Sasajima, S. and Y. Y. Wang, The Recent Research on Loess in China, 242 pp., Kyoto Univ. and Northwest Univ., 1984.

Sun, W., S. K. Banerjee, and C. P. Hunt, The role of maghemite in the enhancement of magnetic signal in the Chinese loess-paleosol sequence: An extensive rock magnetic study combined with citratebicarbonate-dithionite treatment, Earth Planet. Sci. Lett., 133, 493-505, 1995.

Tauxe, L., T. A. T. Mullender, and T. Pick, Potbellies, wasp-waists, and superparamagnetism in magnetic hysteresis, J. Geophys. Res., 101,571584, 1996.

Torii, M., L. Y. Yue, A. Hayashida, K. Maenaka, T. Yokoyama, Y. Y. Wang, and S. Sasajima, Natural remanent magnetization of loess/ paleosol deposits in Luochuan area, in The Recent Research on Loess in China, edited by S. Sasajima and Y. Y. Wang, pp. 32-41, Kyoto Univ. and Northwest Univ., 1984.

Vandenberghe, R. E., E. de Grave, J. J. Hus, and J. Han, Characterization of Chinese loess and associated palaeosol by Mössbauer spectroscopy, Hyp. Interac., 70, 977-980, 1992.

Verosub, K. L., P. Fine, M. J. Singer, and J. TenPas, Pedogenesis and paleoclimate: Interpretation of the magnetic susceptibility record of Chinese loess-paleosol sequences, Geology, 21, 1011-1014, 1993.

Wasilewski, P. J., Magnetic hysteresis in natural materials, Earth Planet. Sci. Lett., 20, 67-72, 1973.

Zhou, L. P., F. Oldfield, A. G. Wintle, S. G. Robinson, and J. T. Wang, Partly pedogenic origin of magnetic variations in Chinese loess, Nature, 346, 737-739, 1990.

K. Fukuma (e-mail: fukuma@jamstec.go.jp) and M. Torii (email: torii@kueps.kyoto-u.ac.jp) 